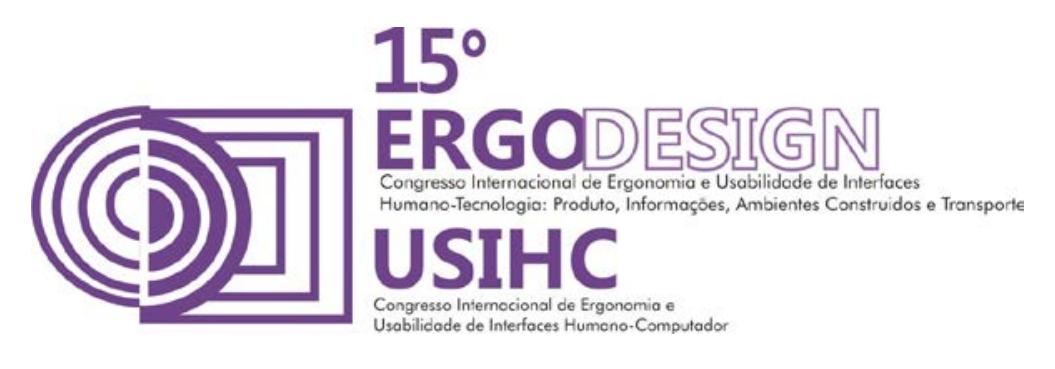

\title{
CONDICIONANTES ERGONÔMICOS APLICADOS AO REDESENHO DE EMBARCAÇÕES PARA PRÁTICA DE CANOAGEM
}

\section{ERGONOMIC RESTRICTIONS APPLIED TO THE REDESIGN OF VESSELS FOR CANOEING PRACTICE}

\author{
BRONDANI, Sergio Antonio (1); \\ JOSE, Tiago Segatto(2) \\ (1) Universidade Federal de Santa Maria, Doutor \\ e-mail: serbrondani@gmail.com \\ (2) Universidade Federal de Santa Maria, Acadêmico de Desenho Industrial \\ e-mail: tiago.segatto@hotmail.com
}

\begin{abstract}
RESUMO
Como principal objetivo, a pesquisa apresenta proposta de desenvolvimento de um projeto de barco adaptado à prática da canoagem e paracanoagem, proporcionando conforto e segurança, condição indispensável a qualquer usuário. A sustentação teórica ficou delineada com a abordagem do Design Universal e condicionantes ergonômicos, considerando os referenciais antropométricos, fisiológicos e comportamentais do indivíduo. Face às condições técnicas e ambientais de análise, foi utilizada pesquisa do tipo experimental, pois pretende-se informar o modo e as causas de como o fenômeno se apresenta. A análise ergonômica auxiliou na certificação das atuais condições para a demanda, tarefa e atividade. Esperamos que os resultados que serão obtidos sejam encorajadores para futuros trabalhos e que possam de alguma maneira agregar qualidade nas futuras embarcações.
\end{abstract}

Palavras-chave: acessibilidade; paracanoagem; ergonomia.

\begin{abstract}
The main objective of this research is a development proposal for a boat design adapted to the practice of canoeing and Paracanoe, providing comfort and security, a prerequisite to any user. The theoretical framework was outlined with the approach of Universal Design and ergonomic constraints, considering the anthropometric, physiological and behavioral references of the individual. Considering the technical and environmental conditions of analysis, the experimental research was used because it is intended to inform the way and causes of the phenomenon. The ergonomic analysis helped certification of current conditions for demand, task and activity. We expect the results to be encouraging for future work and that they can somehow add quality in future vessels.
\end{abstract}

Keywords: accessibility; Paracanoe; ergonomics. 


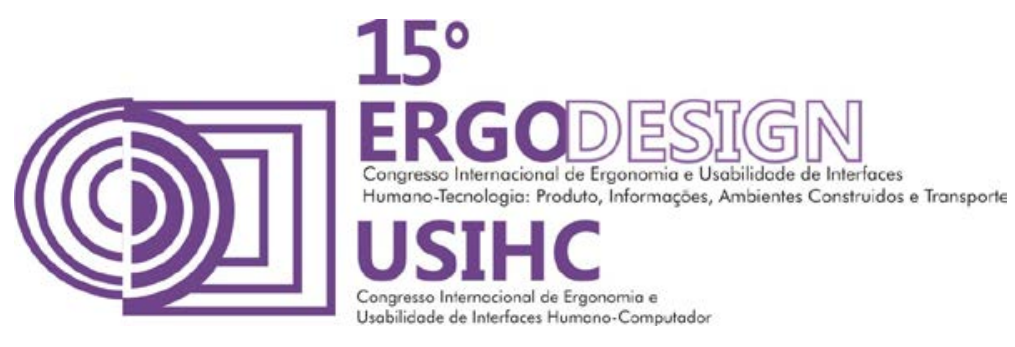

\section{INTRODUÇÃO}

Desde o século XVI tem-se relatos das concepções de canoas e caiaques, tendo seu uso difundido respectivamente pelo índio e o esquimó. O início das competições foi nos jogos olímpicos de Berlim em 1936, mantendo-se até os dias atuais. No Brasil, foi no ano de 1943 que surgiu como prática esportiva. Por falta de infraestrutura, não conseguiu destaque para ser praticado mais amplamente. Em meados das décadas de 70 e 80, com a chegada de caiaques construídos em fibra de vidro, oriundos da Argentina e Europa, é retomada a prática desportiva e surge então a construção de novas embarcações genuinamente brasileiras.

Dentre as diversas modalidades de canoagem, destacamos para essa pesquisa a Paracanoagem Velocidade. Assim sendo, temos como objetivo o desenvolvimento de um projeto de barco com seus subsistemas adaptados à prática da canoagem para qualquer praticante, contemplando a aplicação do Design Universal. Especificamente, irá proporcionar segurança e conforto ergonômico para melhorias de performance da prática esportiva, considerando todos os praticantes, sejam crianças ou adultos. A proposta promoverá a inclusão de todos, mesmo os que apresentam algum tipo de deficiência física. Serão projetados assentos que possibilitem ajustes, suporte de assento que possibilitem ajustes como também travas de fixação par controle de leme e finca-pés.

\section{REVISÃO BIBLIOGRÁFICA}

Como inovação, todo produto é complexo e corre riscos. Portanto, a eficácia dos objetivos e o estabelecimento de metas devem ser considerados para minimizar os riscos do novo produto (BAXTER, 2011). Afirma o autor que o desenvolvimento de novos produtos é necessariamente uma solução de compromisso. Requer pesquisa, planejamento cuidadoso, controle meticuloso e, mais importante, o uso de métodos sistemáticos com abordagem interdisciplinar.

Podemos enquadrar a atividade (prática) em diferentes níveis, pois estas representam a carga de trabalho, as consequências para o praticante e os custos humanos da prática da modalidade esportiva, conforme contextualizado por Moraes e Mont'Alvão (2000).

Afirmações de Gomes Filho (2003) relatam que o desenvolvimento de projetos deve prever principalmente a relação do esforço físico com os parâmetros de velocidade e grau de precisão da ação realizada. Considerando que a canoagem exige maior número de atos operacionais, maior frequência, maior velocidade e menor tempo, podemos defini-la como sendo uma ação complexa. Portanto, a utilização das habilidades, sensibilidade, força, precisão, compatibilidade, sincronismo, treinamento e experiências, são considerados os principais atributos do usuário.

\section{METODOLOGIA}

Foi a partir da Análise Ergonômica consideradas as fases da demanda, tarefa e atividade. A demanda, que tem como objetivo identificar os problemas, foi caracterizada por observações "in loco" da prática desportiva, bem como o registro de comportamento (levantamento de dados) para elaboração parcial do diagnóstico ergonômico. A tarefa requer atenção nas prescrições referente a prática e equipamentos, sendo então observadas as normativas legais (Federação 


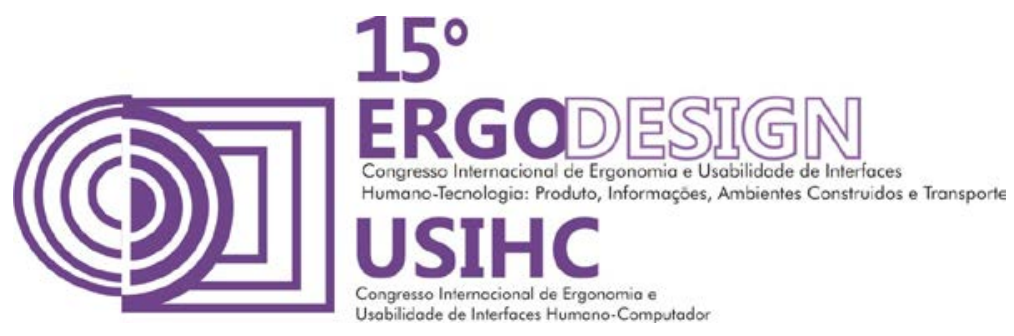

Internacional de Canoagem - FIC), que levam em consideração as condições físicas dos atletas, quando da utilização das pernas, tronco e braços, definindo assim as classes para diferentes modalidades. Também são observadas as regras de peso e tamanho das embarcações. Para avaliação da atividade, foram observadas a prática desportiva com os equipamentos disponíveis no mercado, bem como as adaptações circunstanciais que cada praticante propõe em função das suas condições.

Todas estas análises remetem a pesquisa ao desenvolvimento de um novo projeto, melhor adequado às condições de segurança e conforto do usuário. Atualmente está em fase de prototipagem um suporte móvel e regulável para assento a ser acoplado na embarcação, que possibilite o controle de posição, altura, inclinação e rotação assim como suporte diversos modelos de assentos disponíveis no mercado, proporcionando melhores condições para a prática desse esporte.

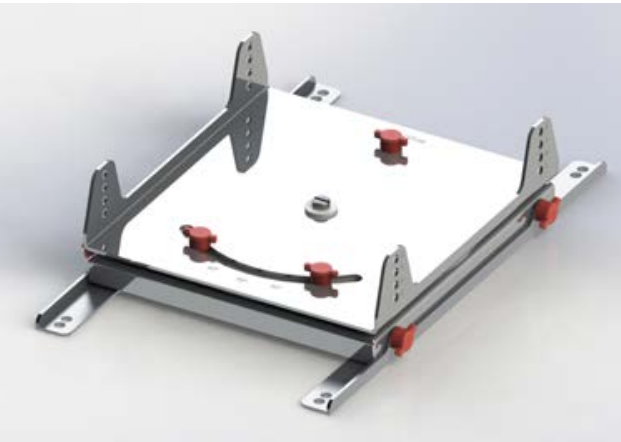

Figura 1 - Suporte Móvel e Regulável para Assento.

\section{RESULTADOS ESPERADOS}

Diante do que foi exposto, é esperado que os desenvolvimentos dos trabalhos possam atender plenamente aos objetivos propostos. Apresentando um produto diferenciado, por certo haverá um reconhecimento maior da importância que tem esta pesquisa, podendo servir como referência para projetos futuros.

Trabalhando com o conceito do Design Universal, a proposta vem ao encontro das políticas sociais hoje praticadas, além de favorecer positivamente a relação entre universidade e comunidade.

\section{REFERÊNCIAS BIBLIOGRÁFICAS}

BAXTER, Mike. Projeto de produto: guia prático para o design de novos produtos. São Paulo: Edgard Blücher, 2011.

GOMES FILHO, João. Ergonomia do objeto: sistema técnico de leitura ergonômica. São Paulo: Escrituras Editora, 2003. 


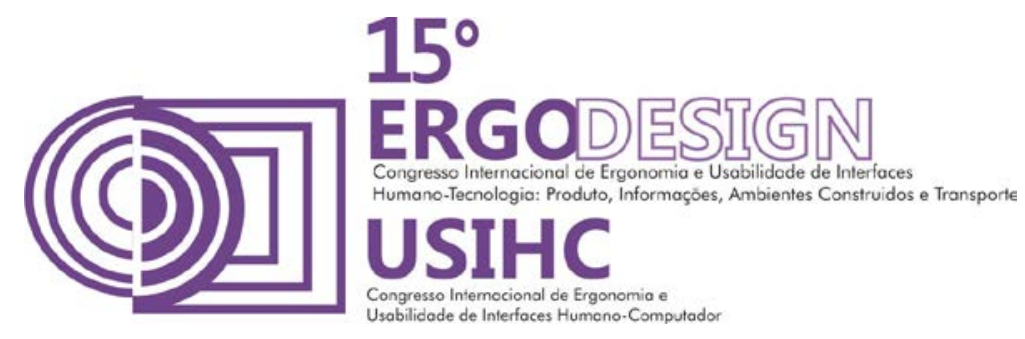

MORAES, Anamaria de; MONT'ALVÃO, Cláudia. Ergonomia: conceitos e aplicações. Rio de Janeiro: 2 $A B, 2000$. 